\title{
Effects of Age and Layers of Trees and Temperature on Nectar Volume and Concentration of Croton Macrostachyus Hochst. ex Delile
}

\author{
Kasim Roba $^{1}$ Getachew Sime ${ }^{2}$ Zufan Bedewi ${ }^{2}$ \\ 1.Holeta bee research center, P.O.Box-22, Holeta, Ethiopia \\ 2.Hawassa University College of natural and computational science P.O. Box. 05, Hawassa, Ethiopia
}

\begin{abstract}
Croton macrostachyus Hochst.ex Delile is a species of the genus Croton, Euphorbiaceae family, commonly known as the spurge family and it is known as major honeybee forages having more nectar and the study was carried out to evaluate effects of its layers, and age and temperature on its nectar volume and concentration. Nectar is a floral resource commonly sought after by plant visitors, because of its nutritional importance. Effects of temperature, layers of trees and plants age on nectar volume and concentration of youngest, medium and oldest age of croton was measured. Results indicated that nectar concentrations and volume of youngest age were no more affected by temperature like that of medium and oldest age. Temperature and age has significant effect on volume $(p=0.0001)$ and their interactions is also significant $(\mathrm{p}=0.012)$.Temperature has significant effects on nectar concentration $(\mathrm{p}$ $=0.000$ ). Oldest plants had highest concentration of $10.1 \mathrm{w} / \mathrm{w}$ morning and afternoon $36.5 \mathrm{w} / \mathrm{w}$ at $4: 00 \mathrm{PM}$ for whereas medium plants had nectar concentration of $5.7 \mathrm{w} / \mathrm{w}$ morning and afternoon $16.7 \mathrm{w} / \mathrm{w}$ and the smallest had nectar concentration of $2.7 \mathrm{w} / \mathrm{w}$ morning and afternoon $9.1 \mathrm{w} / \mathrm{w}$. I conclude that future temperature rise could have negative effect on nectar secreation for honey productions since for croton also no nectar secreation was observed after peak temperature of its nectar secreation that was $30^{\circ} \mathrm{C}$. Studying factors affecting nectar volume and concentrations is important to increase productions and the productivity of honey to generate income and for medicinal value of honey.
\end{abstract}

Keywords: Age of trees, Croton macrostachyus, nectar concentration, nectar volume, temperature, trees layers

DOI: $10.7176 / \mathrm{JNSR} / 11-18-01$

Publication date:September $30^{\text {th }} 2020$

\section{Introduction}

Croton macrostachyus Hochst.ex Delile is a species of the genus Croton., Euphorbiaceae family, commonly known as the spurge family (Obey et al.,2018).C.macrostachyus, known as Broad-leaved croton in English, is named by various vernacular names in the different areas of Ethiopia (Meresa et al.,2019). It occurs in dry, moist and wet Weynadega and Dega as well as in upper altitudes of Dry Kolla agro climatic zones at altitudes between 1,100 and 2,500 m.a.s.l. It is associated with Juniperus-Podocarpus (Alemayehu, 2018). Nectar concentration is highly influenced by temperature (Rutikang et al.,2016). The sugar content of nectar is primary interest of botanists, examining the costs and benefits of allocation of resources to pollinator attraction to pollinate crops (Dong et al., 2012).Nectar is a floral resource commonly sought after by plant visitors such as insects, birds and small mammals, because of its nutritional importance (Adjaloo, 2015). Rate of nectar secretion is influenced by both age and environmental factors, from which relative humidity is the most important (Dong et al., 2012). A significant effect of temperature was found on nectar secretion, with a negative effect of very high temperatures in all species (Takkis et al.,2018).The variation in nectar volume and concentration are affected at ecological and evolutionary levels ,plant mechanisms and by their pollinators' physiology (Stoner et al., 2016). Nectar production entails a cost to the plant and nectar removal naturally occurs in all animal-pollinated species (Dong et al., 2012). Foraging behaviour is the distinctive behaviours of Apis mellifera and it depends on environment and time (Aboushaara,2016). Diptera are important flower visitors and pollinators for many plant species in variety of habitats based on temperature and physiological constraints (Inouye et al.,2015). The response of nectar secretion to external environmental and variation in nectar traits associated with intrinsic plant characteristics (Lu et al., 2015). It was compared that the changes in nectar secretion under temperatures expected by the end of the century and estimated the effect of climate warming on nectar secretion of plants flowering in different seasons and of very high temperatures has negative effects in all species (Takkis et al.,2018). Nectar secretion was strongly influenced by plant age (Cawoy,2018). Nectar concentration and volume of Callistemon citrinus.L were affected by age of plants and temperature (Kasim, 2019). Variation of nectar production across different stages of gender in Aconitum gymnandrum highlights the effect of flower age during development of flowers from male to female, middle and late stage of male phase had more nectar volume than other stages of gender, although there was no significant difference in mean nectar volume between two sexual phases (Lu et al., 2015). In the case of secreting hairs of the bean leaf this optimum is $20^{\circ} \mathrm{C}$, in the Abutilon nectary it is $26^{\circ} \mathrm{C}$ and optimum temperature for amount of secretion lies between $20^{\circ} \mathrm{C}$. and $25^{\circ} \mathrm{C}$ (Stoner et al., 2016). More sugar accumulated in a dry atmosphere can be 
utilized, its respiratory destruction being retarded by the low temperature and the evidence points to the conclusion that at a uniform temperature the secretion of nectar is a balance between two factors,- the accumulation of sugar in and near the flower under the influence of low temperatures and increasing permeability of the plasma membrane under the influence of high temperature (Stoner et al., 2016). The east African highland Musa cultivars having the highest nectar volume had the lowest sugar concentration, while the dessert types with the least nectar volumes had the highest sugar content (Rutikanga et al.,2016). The contribution of a bee plant species to honey production depends on the plant's nectar secretion quality and quantity, which is mainly governed by biotic and abiotic factors (Adgaba et al., 2017).Volume and concentration of nectar vary among plant species and different varieties of the same species may also differ greatly in nectar sugar concentration (Das et al.,2014). Plants' ability to sense their environment and respond to it is critical for their survival (Veits et al., 2018).

\section{Materials and methods}

\subsection{Selection of trees' age and caging their inflorescences for nectar collections}

Nectar sugar concentration in the nectar produced per flower was measured in the field using a hand refractometer (American Optical 10431, Buffalo, NY; range concentration 0-45, BRIX units, at the time of peak nectar secretion in the day, as sucrose equivalent (Das et al., 2014). Nectar concentration is measured with refractometer, giving a reading as percent sucrose equivalents $(\mathrm{w} / \mathrm{w})$. The reading threshold of the refractometer. Slender microcapillary tubes are recommended for withdrawing nectar and a hand held sucrose refractometer, capable of operating with very small fluid volumes, is used for measuring concentration.

\subsection{Collection and measuring, nectar volume and concentration of Croton macrostachyus}

Before blooming inflorescences were chosen randomly in experimental designs. Flowers were caged with insect prove in order to exclude visiting insects (covered flowers) until they open their heads and most of them opened after three days. Nectar volume and concentrations was taken and measured (Kasim, 2019). Each sample flowers was representing separate layers of the trees. Nectar volume was measured by sensitive balance and unit conversions was carried out into microliter since measuring nectar volume by micropipettes greatly differs from measurement of sensitive balance when compared since air bubble affects reading and this methods is the most accurate than using micropipette or microcapillary directly. To do so, nectar was collected by micropipette tips and brought to laboratory by putting in icebox after inserted to pendroph

\subsection{Sample size of the experiment}

The idea behind Maximum variation sampling was used to look at a subject from all available angles, thereby achieving a greater understanding on topic of the study (Etikan et al.,2017). Maximum variation sampling is a search for variation in perspectives, ranging from those conditions that are typical through to those that are extreme in nature. Nine trees were selected: three oldest trees, three medium trees and three youngest trees and three layers were taken based on their branches nine to eight for older, six to seven for medium and two to three for youngest and these trees were selected from the same environmental conditions .

\subsection{Naming and labeling of trees layers}

After trees and layers selected purposively the layers were named as layer one or bottom layer represented as AL1 (layer one in afternoon), AL2 (layer two in afternoon) and AL3 (layer three in afternoon) whereas for the morning ,ML1 ( layer one in the morning), ML2 ( layer two in the morning) and ML3 (layer three in the morning).

\subsection{Data compilation and analysis}

Sequences of steps were used: First, all plants in a population were counted and nine trees: three medium, three youngest and three oldest 'were selected and nectar concentration and volume was collected and parameters like temperature, age, layers of trees were sampled. After sampling, data were inserted to computer Microsoft excel 2010 and imported to R software version 3.44. Multilevel analysis was used to see interaction between variables affecting nectar volume and concentration of C.macrostachyus. Anova was used to see significance of interaction of these factors, it involves selecting candidates across a broad spectrum relating to the topic of study (Etikan $e t$ al.,2017).

\section{Results and Discussions}

Interaction of nectar concentration (\%), layers of trees and nectar volume of C. macrostachyus Hochst.ex Delile indicated layers of trees affected nectar volume and concentration (Figure 1). Nectar volume has significant effects on nectar concentration with $(\mathrm{p}=0.000)$ and trees layers has significant effects on nectar concentration with $(\mathrm{p}=$ $0.000)$. Interactions of trees layers and nectar volume has significant effects on nectar concentration with $(p=$ 0.00001 ) which means lower layers has higher nectar volume than top layers that exposed to sunlight intensity and they have direct effect on nectar concentration. In the morning nectar volume of layer one or ML1 was higher than 
the rest of the layers for all age of plants, but in afternoon lowest at layer three or AL3 for all ages of plants. Nectar volume and concentration are inversely proportional to each other. Similar results was reported by (Adjaloo, 2015).

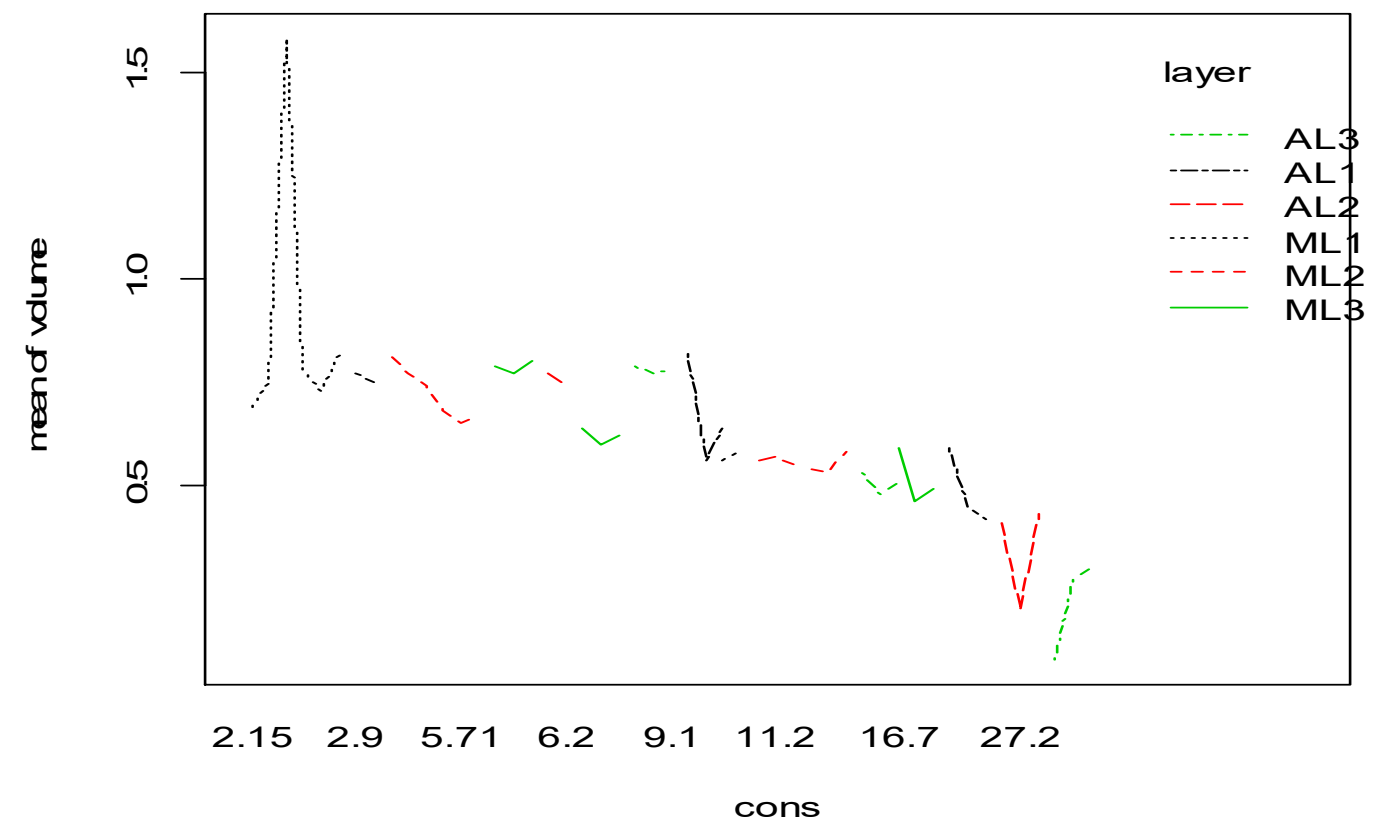

Figure 1: Interaction of nectar concentration (\%), tree layers and nectar volume of Croton macrostachyus

Plants age has significant effects on nectar concentration of croton $(p=0.000)$ and also layers of trees has significant effects on nectar concentration $(\mathrm{p}=0.000)$ (Figure 2). Interaction of plants age and layers of trees has $\mathrm{s}$ significant effect on nectar concentration $(p=0.0004)$. In the afternoon, top layer of the oldest plants had highest nectar concentration than the rest of the layers of all ages, but in the morning, top layers had lower nectar concentration than in the afternoon for this top layers. This infers difference in intensity of sunlight reaching to the layers differs their nectar concentrations and layers of trees have direct effect on nectar concentrations. Oldest, medium and youngest plants had highest concentration of $10.1 \mathrm{w} / \mathrm{w}, 5.72 .7 \mathrm{w} / \mathrm{w}$ in the morning respectively. Whereas in the afternoon/w $36.5 \mathrm{w} / \mathrm{w}, 16.7 \mathrm{w} / \mathrm{w} 9.1 \mathrm{w} / \mathrm{w}$ at $4: 00$ PM respectively. Plants age has significant effect on the nectar concentration of croton. This result is analogous to reports on Callistemon citrinus L that plants age has significant effects on nectar concentration for older, medium and younger ages of Callistemon citrinus $\mathrm{L}$ (Kasim, 2019) .

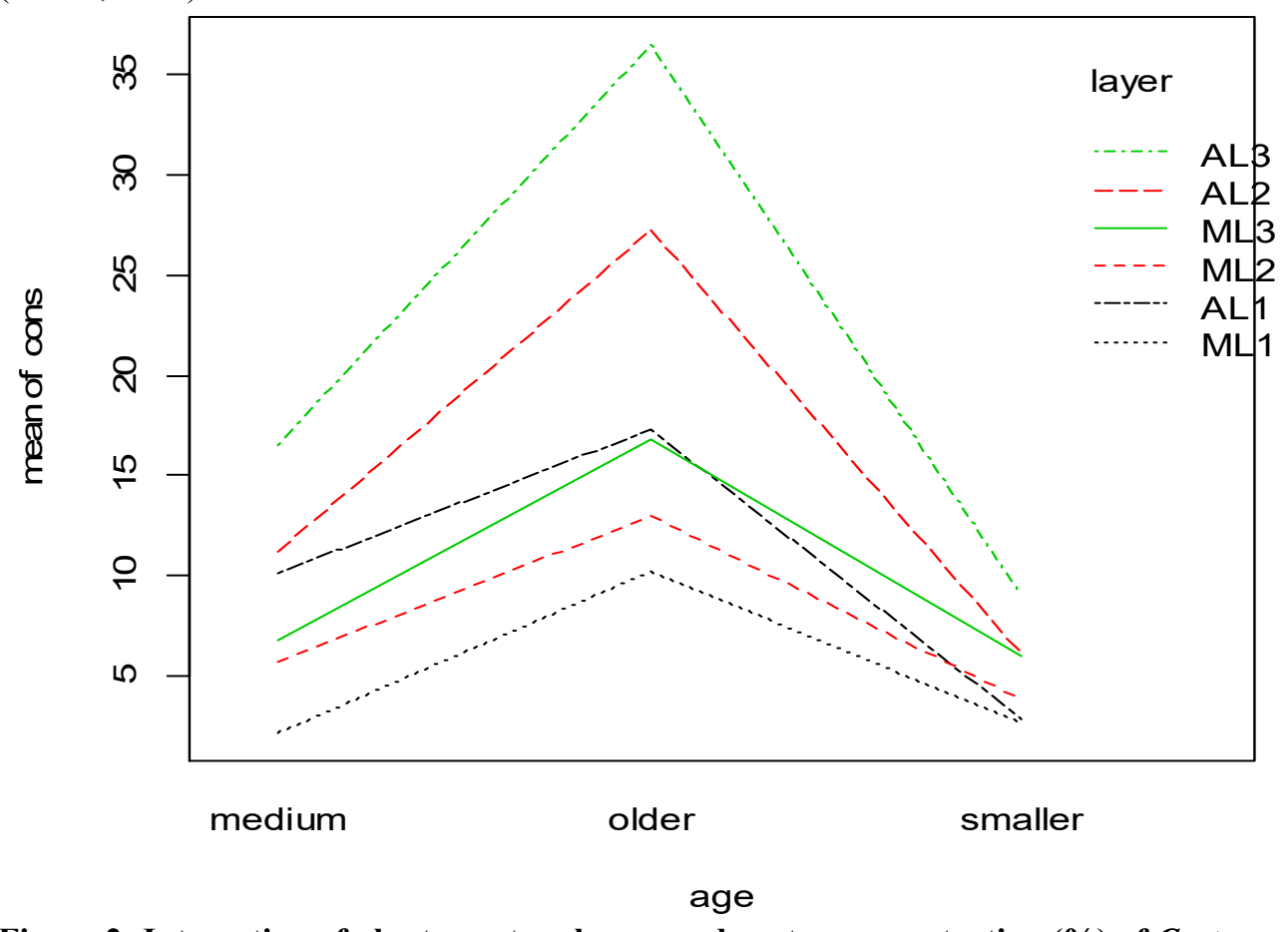

Figure 2: Interaction of plant age, tree layers and nectar concentration (\%) of Croton macrostachyus 
Plants age has significant effects on nectar volume of croton $(p=0.00002)$ and layers of trees has significant effects on nectar volume of croton $(\mathrm{p}=0.002)$, but their interaction has no significant effects on nectar volume $(\mathrm{p}>$ 0.05) (Figure 3). The youngest plants had highest nectar volume than medium and oldest age of plants. The nectar volume of medium and oldest age of plants increased in the morning at layer one and started decreasing from layer two to layer three. This implies layers of trees and age of plants directly affected nectar volume. Plants age has significant effects on nectar volume. Similarity it was reported that nectar secretion was strongly influenced by plant age (Cawoy,2018).

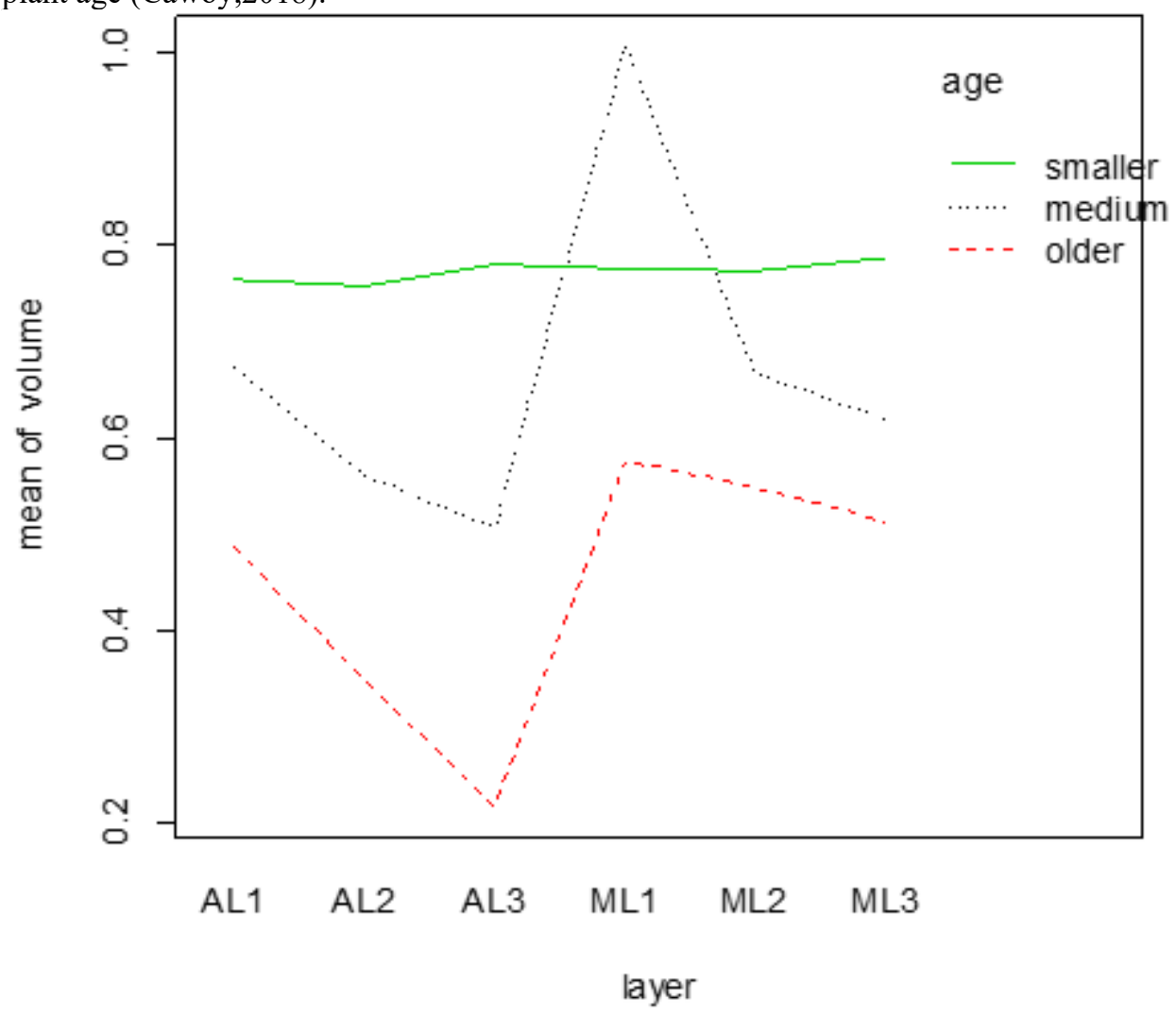

Figure 3: Interaction of tree layers, plant age and nectar volume of Croton macrostachyus

Temperature and age has significant effect on volume $(\mathrm{p}=0.0001)$ and their interactions is also significant $(\mathrm{p}=0.01145)$. Lowest nectar volume was recorded at highest temperature, but highest nectar volume was recorded at lowest temperature (Figure 4). AL3 or layer three in afternoon had lowest nectar volume than AL2 or afternoon layer two or medium layer and AL1 or afternoon layer one whereas ML1 or morning layer one had highest nectar volume than ML2 or morning layer two and ML3 . this might be due to light intensity reaching to these layers at different time that enable lowest layer or ML3 to have highest nectar volume since it is shaded by trees branches and no more light intensity reach to this layer. Nectar volume was influenced by temperature this result is similar with the reports that nectar volume of Callistemon citrinus was influenced by temperature (Kasim,2019). 


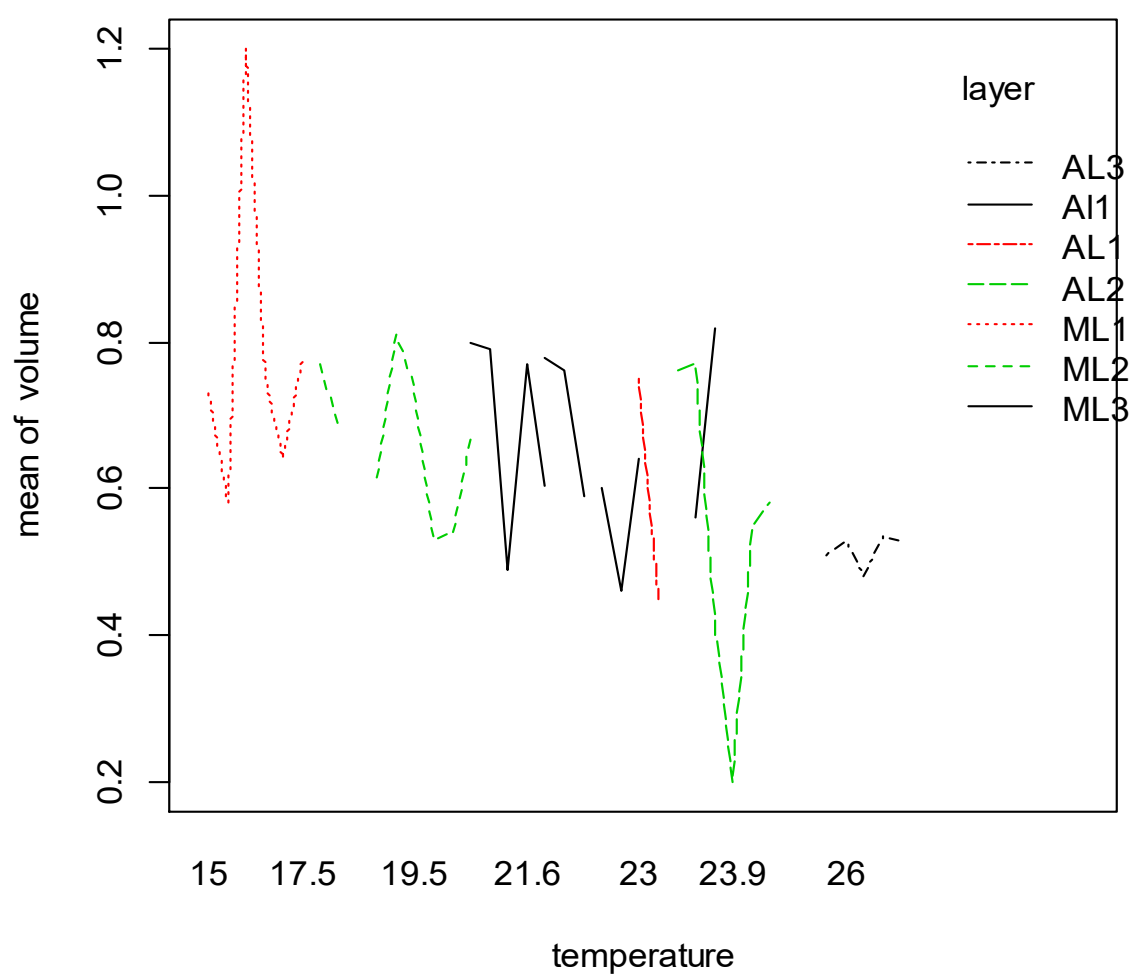

Figure 4: Interaction of tree layers, plant age and nectar volume of Croton macrostachyus

Temperature has significant effects on nectar concentration $(\mathrm{p}=0.000)$. Oldest plants had highest concentration $(\mathrm{w} / \mathrm{w})$ morning and afternoon whereas medium age of plants had medium nectar concentration $(\mathrm{w} / \mathrm{w})$ and the youngest or smaller age of trees had lowest nectar concentration $(\mathrm{w} / \mathrm{w})$ morning and afternoon (Figure 5).This implies nectar concentrations of croton was affected by age of plants similar results was reported that nectar concentrations is strongly influenced by age of plants (Cawoy,2018). Plants age has significant effects on nectar a concentration of croton. Nectar concentration was highly influenced by temperature. Similar results was reported by (Rutikang et al.,2016).

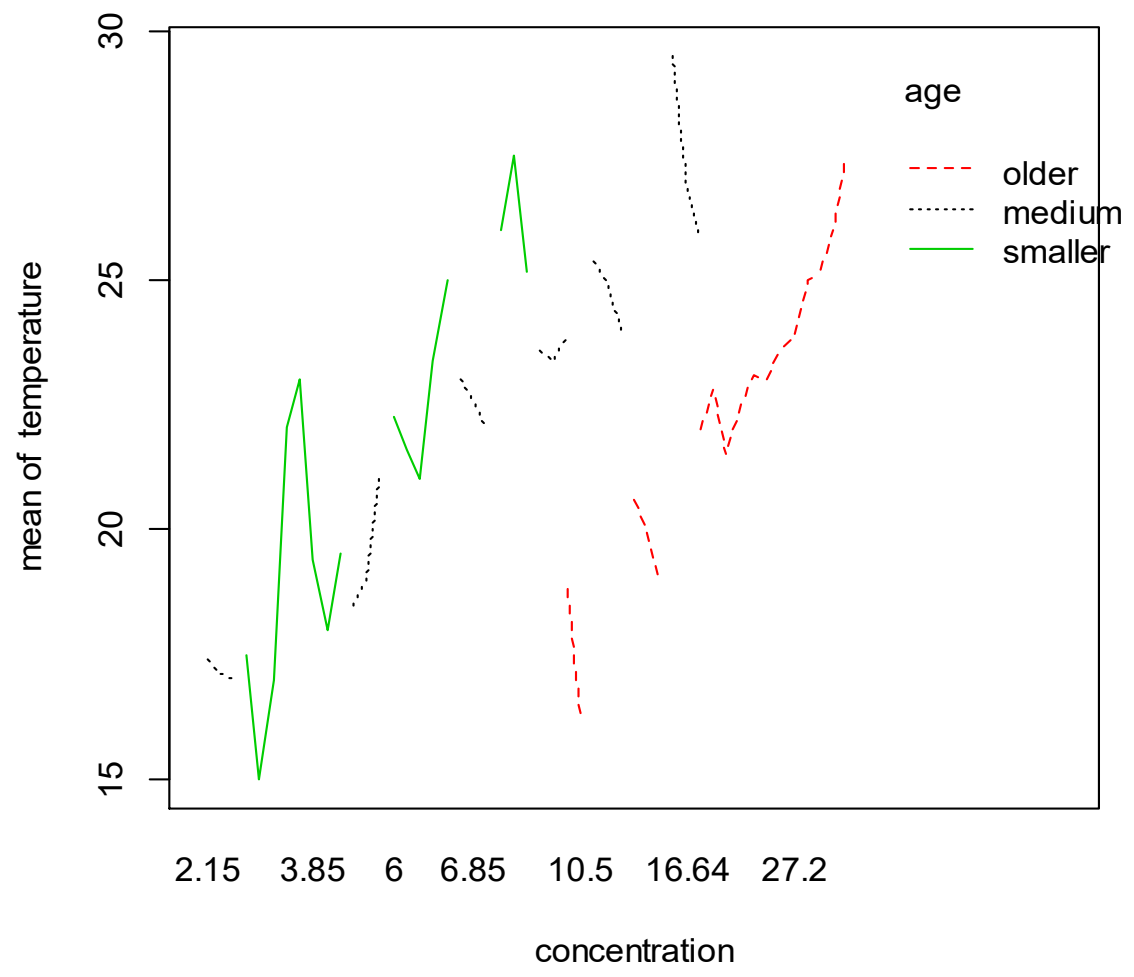

Figure 5: Interaction of tree layers, plant age and nectar volume of Croton macrostachyus

Temperature has significant effects on nectar concentration of croton with $(p=0.000)$. AL3 or top layer had 
highest nectar concentration than medium and lowest layer that might be due to high light intensity reaching to top layers those directly exposed to sunlight than lower or bottom layers those shaded by trees branches (Figure 6). In the afternoon, top layer had highest nectar concentration than the rest of the layers of all ages, but in the morning, top layers had lower nectar concentration than in the afternoon for this top layers. This infers difference in intensity of sunlight reaching to the layers differs their nectar concentrations and layers of trees have direct effect on nectar concentrations. Nectar concentration of Croton macrostachyus is highly influenced by temperature. Similar results was reported that nectar concentration.is highly influenced by temperature (Stoner et al., 2016).

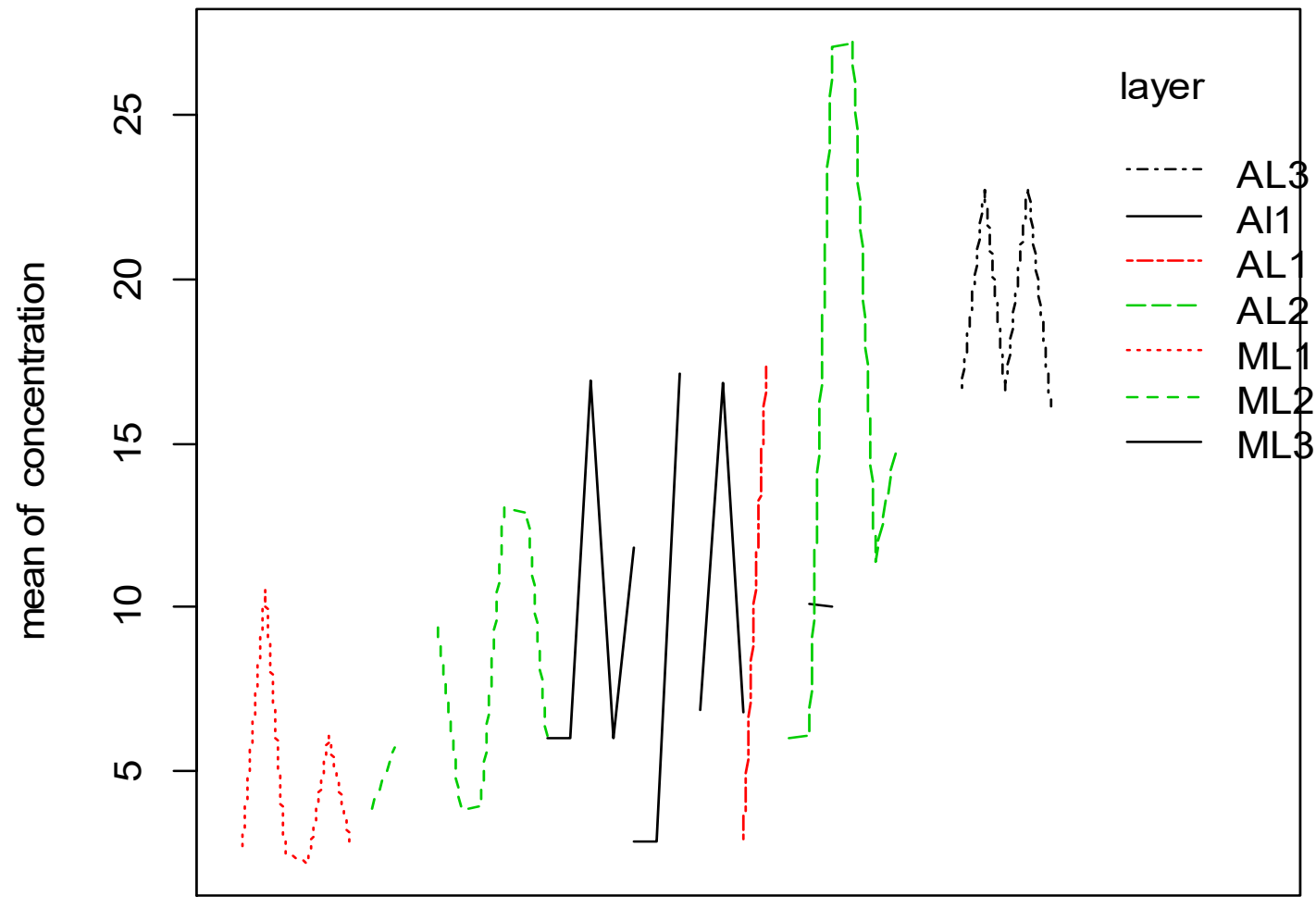

\section{$\begin{array}{lllllll}15 & 17.5 & 19.5 & 21.6 & 23 & 23.9 & 26\end{array}$}

\section{temperature}

Figure 6: Interaction of tree layers, plant age and nectar volume of Croton macrostachyus

Temperature and age has significant effect on volume $(\mathrm{p}=0.0001)$ and their interactions is also significant $(\mathrm{p}=0.012)$.Oldest age had highest nectar concentration than medium and youngest age of C.macrostachyus Hochst. ex Delile (Figure 7). Youngest or smallest age had lowest nectar concentration than medium and oldest age that might be due to bleeding of water from several tissues or more water absorption capacity of these youngest from soil than medium and oldest age .This implies oldest age having highest nectar concentrations is important for nectar production since highest nectar concentration can be easily converted to honey by bees whereas youngest age are less important for honey production having lowest nectar volume when compared to medium and oldest age. Temperature highly influenced nectar secreation. Similarly it was reported as significant effect of temperature was found on nectar secretion, with a negative effect of very high temperatures in all species (Takkis et al.,2018). 


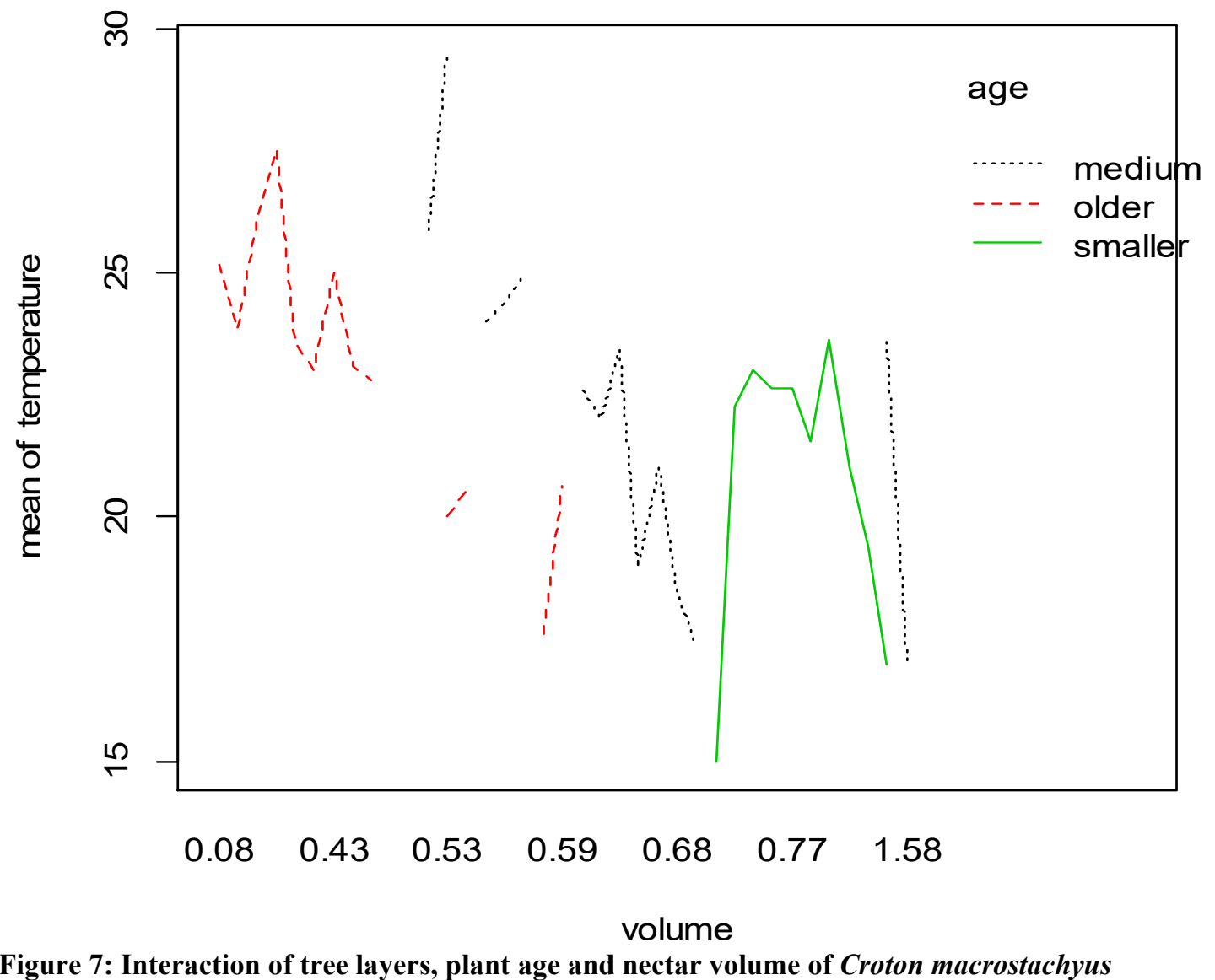

\section{Conclusions}

Nectar concentrations and volume of medium and oldest age of C. macrostachyus was affected by age of plants, temperature, and layers of trees, but for youngest plants nectar concentration was not affected by temperature. Youngest, medium and oldest ages had nectar concentrations of $9.1 \mathrm{w} / \mathrm{w}, 16.7 \mathrm{w} / \mathrm{w}$ and $36.5 \mathrm{w} / \mathrm{w}$ respectively in the afternoon and in the morning $2.7 \mathrm{w} / \mathrm{w}, 5.7 \mathrm{w} / \mathrm{w}$ and $10.1 \mathrm{w} / \mathrm{w}$ respectively. I conclude that future temperature rise could have negative effect on the nectar production of plant species, since for Croton also maximum temperature to produce nectar was $30 \mathrm{C}^{0}$ and above this temperature no nectar production was seen and may have negative effects on honey productions since nectar quality will be lost if climate changes since temperature rises. For three ages of $C$. macrostachyus lower layers recorded lower nectar concentration and higher nectar volume when compared to the medium and top layers of the trees in the morning. In the afternoon higher nectar concentration and lower nectar volume was recorded in top layer than the medium and lower layers of the trees. This study is one of the first where factors affecting nectar volume and concentrations like age of trees, layers of trees and temperature are quantified in Ethiopia. A future study is necessary to pinpoint factors affecting nectar volume and concentration for honey productions.

Conflict of interest statement: I declare that I have no conflict of interest and it is my original work.

\section{Acknowledgements}

First and foremost,I am grateful to acknowledge my advisors Dr.Getachew Sime and Dr.Zufan Bedewi Department of Biology,College of Natural and Computational Sciences,Hawassa University for supervision, critical comments, suggestion, and valuable time spent with me in the laboratory and field work and devoted time to add essential points to improve the quality of my research paper. I am very much thankful to Mr. Mosisa Daba and Tigist for their support during laboratory work and Hamid Imam for his support while I was entering data. I need to acknowledge Dr. Abiot Deddefo who was encouraging me on everything for my success and Dr. Feto Esmo Beriso general director of Oromia research institute for his help in teaching me R software that helped me to analysis my thesis data. I need to concede Dr.Zemzem Ahmed and her mother Medina Abdo Jilo tendered inspiration while I was editing thesis for submission. I need to confess researcher Osho Tibesso from USA for his fatherly advice and my friend researcher Muhammed Abu, Dr.Musa Jarso director of Holeta agricultural research institute and Mr. and finally I need to acknowledge Oromia agricultural research institute for financial support for thesis work in all aspects. 


\section{References}

Abou-shaara, H. (2016). The foraging behaviour of honey bees, Apis mellifera : a review. The Foraging Behaviour of Honey Bees, Apis mellifera: A Review, January 2014. https://doi.org/10.17221/7240-Vetmed

Adgaba, N., Al-ghamdi, A., Tadesse, Y., Getachew, A., Awad, A. M., Ansari, M. J., Owayss, A. A., Eldin, S., Mohammed, A., \& Alqarni, A. S. (2017). Nectar secretion dynamics and honey production potentials of some major honey plants in Saudi Arabia. Saudi Journal of Biological Sciences, 24 (1), 180-191. https://doi.org/10.1016/j.sjbs.2016.05.002

Adjaloo, M. K. (2015). Nectar production dynamics in two melliferous plant species. Nectar Production Dynamics in Two Melliferous Plant Species, January.

Alemayehu, G. (2018). Ethnobotanical profile of Croton macrostachyus ( Euphorbiaceae ) in Ethiopia : Review of the literature. Ethnobotanical Profile of Croton Macrostachyus ( Euphorbiaceae ) in Ethiopia : Review of the Literature, 209-222.

Cawoy, V. A. L. E. R. I. E. (2018). Morphology of Nectaries and Biology of Nectar Production in the Distylous Species Fagopyrum esculentum. February, 675-684. https://doi.org/10.1093/aob/mcn150

Das, M., Vidal, G., Jong, D. D. E., Wien, H. C., \& Morse, R. A. (2014). Nectar and pollen production in pumpkin ( Cucurbita pepo L .). Nectar and Pollen Production in Pumpkin ( Cucurbita Pepo L .), January. https://doi.org/10.1590/S0100-84042006000200008

Dong, K., Dong, Y., Su, R., Zhang, J., Qing, Z., Yang, X., Ren, X., Ma, Y., \& He, S. (2012). Effect of nectar reabsorption on plant nectar investment in Cerasus cerasoides. Effect of Nectar Reabsorption on Plant Nectar Investment in Cerasus Cerasoides, November 2011, 251-256.

Etikan, I., Musa, S. A., \& Alkassim, R. S. (2017). Comparison of Convenience Sampling and Purposive Sampling Comparison of Convenience Sampling and Purposive Sampling. February. https://doi.org/10.11648/j.ajtas.20160501.11

Inouye, D., Larson, B. M. H., \& Kevan, P. (2015). — Review — Flies and flowers iii : ecology of foraging and. review - flies and flowers iii : ecology of foraging and, January.

Kasim ,R., (2019). International Journal for Research in Agricultural and Food Science ISSN: 2208-2719. International Journal for Research in Agricultural and Food Science ISSN: 2208-2719, 11, 1-13.

Lu, N., Li, X., Li, L., \& Zhao, Z. (2015). Variation of nectar production in relation to plant characteristics in protandrous Aconitum gymnandrum Study species. 8(2), 122-129. https://doi.org/10.1093/jpe/rtv020

Obey, J. K., Ngeiywa, M. M., Kiprono, P., Omar, S., Wright, A. Von, Kauhanen, J., \& Tikkanen-kaukanen, C. (2018). Antimalarial Activity of Croton macrostachyus Stem Bark Extracts against Plasmodium berghei In Vivo. Antimalarial Activity of Croton macrostachyus Stem Bark Extracts against Plasmodium berghei In Vivo, 2018.

Meresa, A., Ashebir, R., Gemechu, W., \& Teka, F. (2019). Ethno medicinal uses , phytochemistry and anti-malarial effect of Croton Ethno medicinal uses, phytochemistry and anti- malarial effect of Croton macrostachyus ( Bisana ): A review. Ethno Medicinal Uses, Phytochemistry and anti-malarial effect of Croton ethno medicinal uses, phytochemistry and anti- malarial effect of Croton macrostachyus ( Bisana ): A Review, March.

Rutikanga, A., Tusiime, G., Night, G., Ocimati, W., \& Blomme, G. (2016). Variation in nectar volume and sugar content in male flowers of Musa cultivars grown in Rwanda and their non-effect on the numbers of visiting key diurnal insect vectors of banana Xanthomonas wilt. Variation in Nectar Volume and Sugar Content in Male Flowers of Musa cultivars Grown in Rwanda and Their Non-Effect on the Numbers of Visiting Key Diurnal Insect Vectors of Banana Xanthomonas Wilt, 11(8), 607-623. https://doi.org/10.5897/AJAR2015.10476

Stoner, K. E., Flores-ortiz, C. M., Ayala-berdón, J., Rodríguez-pe, N., Munguía-rosas, M. A., Sánchez-cordero, V., \& Schondube, J. E. (2016). Revista Mexicana de Biodiversidad Factors affecting nectar sugar composition in chiropterophilic plants. Revista Mexicana de Biodiversidad Factors Affecting Nectar Sugar Composition in Chiropterophilic Plants, 87, 465-473. https://doi.org/10.1016/j.rmb.2016.03.002

Takkis, K., Tscheulin, T., \& Petanidou, T. (2018). Differential Effects of Climate Warming on the Nectar Secretion of Early- and Late-Flowering Mediterranean Plants. Warming on the Nectar Secretion of Early- and LateFlowering Mediterranean Plants, 9(June), 1-13. https://doi.org/10.3389/fpls.2018.00874

Veits, M., Khait, I., Obolski, U., Zinger, E., Boonman, A., Goldshtein, A., Ben-dor, U., Estlein, P., Kabat, A., Peretz, D., Ratzersdorfer, I., Krylov, S., Chamovitz, D., Sapir, Y., Yovel, Y., Hadany, L., \& Security, F. (2018). I . Title page. : : Flowers respond to pollinator sound within minutes by increasing nectar sugar concentration. 